\title{
A Comparative Study of Gameplay of Different Sets of Players in an Engineering Mapping Game
}

\author{
Anirban Chakraborty (Student Member, IEEE)*, Zachary Simpson, Rani Deepika Balavendran Joseph (Member, \\ IEEE), and Gayatri Mehta (Senior Member, IEEE) \\ Department of Electrical Engineering \\ University of North Texas \\ *Email: anirbanchakraborty [AT] my.unt.edu
}

\begin{abstract}
Educators in the STEM (science, technology, engineering, and mathematics) field are constantly employing different tools to make the process of education streamlined and fun. The digital gaming platform also called e-gaming platform has evolved as one of the key tools to make STEM education more accessible to students. UNTANGLED III is such an egaming platform that is based on STEM concepts and aims to bring in players from all educational backgrounds under a common platform. The data obtained from the game gave us insights on how males and females play the game. It has answered whether there are any significant differences in the gameplay strategies between males and females. The data pertaining to the types of puzzles that players, from both genders, chose and played, was also obtained. Males and females had no stark differences in the strategies that they used in solving the puzzles. They used similar kinds of moves and in fact solved similar kinds of puzzles of similar difficulty levels. During their gameplay sessions, both the males and the females visualized similar patterns in the puzzles as evident in their final solution. The performance of players from both the genders, based on the gameplay data was at par. Suggestions obtained from the current players and outreach events hold the key to increasing the overall participation in the game.
\end{abstract}

Keywords - Educational games, Engineering games, Mapping, Games with a purpose, UNTANGLED III

\section{INTRODUCTION AND BACKGROUND}

Electronic games (e-games) have evolved considerably over the past several years to the extent that children aged less than eleven years occupy a considerable span of their day spending time on playing e-games (Generation M2: Media in the Lives of 8 - to 18-Year-Olds). An exhaustive evidencebased analysis with convincing data regarding the availability of the e-gaming platform to children has already been published [1]. Exposure of children to the e-gaming platform can be utilized as a medium to entertain and educate them. Among many, the platform of massive multiplayer online roleplaying games (MMORPGs) has piqued the interest of researchers to use it as a medium of education [2]. E-games have a massive reach and those developed with an educational intent can improve the learning capabilities of the participants by enhancing their brain chemistry [3]. STEM-based e-games can also attract more children in pursuing their education towards STEM disciplines [4] and can also become an indispensable resource for teaching as the theories and concepts are difficult to master for a beginner [5], [6]. Use of the interactive learning methodologies besides the traditional face-to-face learning have been documented very recently too [7]. Such inclusion has enabled a better understanding of the STEM concepts and an increase in student engagement.

However, concerns were raised that e-games are appealing more to the males [8], [9] specifically a 15-year-old male [4]. The book "From Barbie to Mortal Kombat" [10] also discusses a similar trend. The American Association of University Women Educational Foundation conducted a series of studies to find the participation of females in e-games in the year 1992 , 1998 and 2000 and pointed out that STEM disciplines have always witnessed higher male participation. Various literature has put considerable efforts in uncovering the cause of the lack of female population in STEM and the lack of female involvement in game-based interactive learning. Involvement in other activities [9] and getting anxious while using computer-related technologies [11] are some well- documented reasons for the same. The existence of e-games that are more male-oriented has also been pointed out as another major factor of lack of female participation [12]. In an attempt to assess the convergent validity of a virtual environment (VE) navigation learning task on a group of healthy adults, it was observed that females preferred playing games that were easier to learn [13]. Another team tried to gain knowledge about the spatial ability of human beings from the gender perspective by using computer-simulated scenarios and found that males performed better than the females [14]. Females, however, excelled men in collaborative and intuitive tasks [15] thus hinting that females will excel men in an e-gaming platform that is developed on the essence of collaboration [16].

In this paper, an online interactive puzzle game, UNTANGLED III, is explored to examine how different sets of players, for example, males and females from various educational backgrounds (STEM or non-STEM) play several puzzles with gaming constraints that motivate them to use their cognitive skills. The puzzles are presented increasing level of difficulty, however, the puzzles may be completed in any order. For both genders, the gameplay data is analyzed to observe similar trends in the solved puzzles based on difficulty 
and gameplay decisions. The data from UNTANGLED III was collected from outreach and in-house events as well as worldwide competitions since its online deployment in August 2017. Based on the gameplay data it was observed that male participation was more than that of female in this e-gaming platform.

\section{OVERVIEW OF THE UNTANGLED III GAMING FRAMEWORK}

UNTANGLED III is the successor of UNTANGLED [17][20] and UNTANGLED II: Unbound. These games belong to the genre of Games with a Purpose (GWAP). Games falling under the category of GWAP aim to harness the intellectual ability of citizen scientists, irrespective of their educational background to find the solution of several unanswered questions. Over the years, GWAP has gained extreme popularity in the scientific world. Among various notable games falling under the umbrella of GWAP, Foldit [21], a protein structure prediction and design game and Eterna [22], an RNA molecular design game has fascinated many scientific minds. Both these gaming platforms have used crowdsourcing to tunnel in human intelligence and to use that intelligence in answering some unanswered questions in their respective domain.

UNTANGLED III is a puzzle-based game where players do not require any special educational background to solve the puzzles. Players are presented with a web page where they have the choice to choose from several puzzles or levels as shown in Figure 1. Each level includes a gaming grid that houses an arrangement of several connected blocks or nodes of a distinct color. The connections can be white or red. A red connection is considered a violation that must be resolved to white. The gaming grid dimension is also dynamic and adjusts automatically as per necessity when a player plays the game.

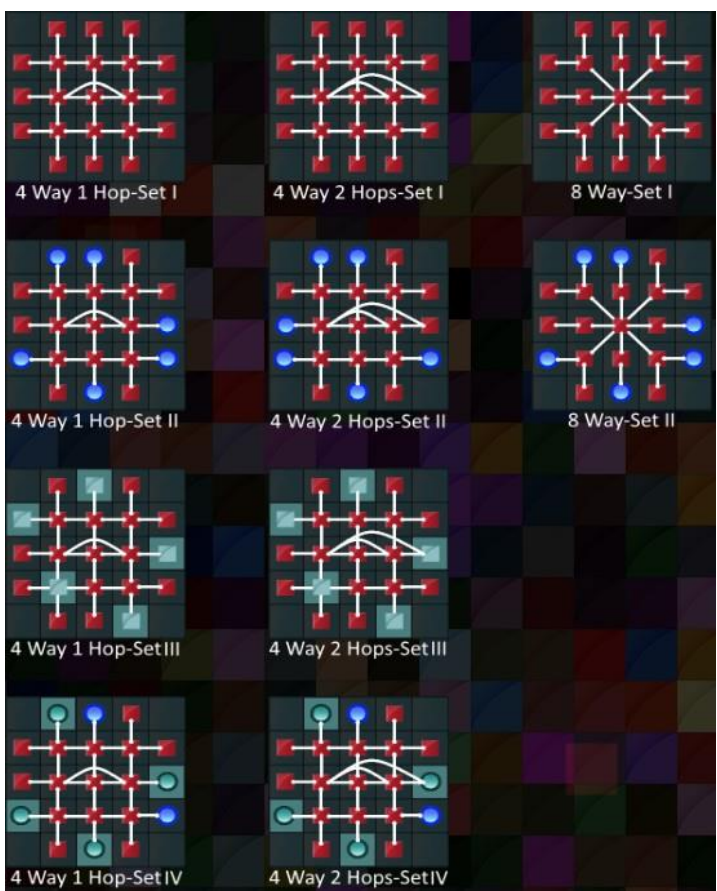

Figure 1 - Different sets of games in UNTANGLED III

Each puzzle has been taken from some abstracted concepts of electrical engineering like signal and image processing. Examples of such applications are Sobel, Laplace, GSM, ADPCM decoder and ADPCM encoder, IDCT row and IDCT col. These applications can be represented in the form of a dataflow graph (DFG). Much like the puzzles, the DFGs of these applications comprises a collection of connected blocks. The connections are also known as the edges of the DFG. For an Electrical Engineer, the blocks represent Arithmetic and Logic Units (ALUs), dedicated multipliers, pass-throughs, and other computational elements while the edges represent interconnects or wires. However, prior knowledge of the technical details is not necessary to play the game.

Players move the blocks in the grid space and come up with a solution that is more compact, devoid of any aforementioned interconnect violations and consume less power. As a result, the interconnect lengths reduce, and the parent and child nodes live close to each other. Players are awarded incentives in the form of stars during the gameplay when they resolve a violation and achieve a certain efficient block arrangement. This kind of incentives motivates the player towards a more efficient solution of the puzzle.

\section{SETS OF PUZZLES CONSIDERED IN THE EXPERIMENTAL STUDY}

The game is divided into various sets as shown in Figure 1 and each of these sets are chosen for the experimental study that has been presented in this paper. Every set has unique characteristics that are elaborated below: 


\section{A. SET - I}

This set contains homogeneous puzzles. It means all the blocks used in SET - I are alike and are represented by red squares. These puzzles support three kinds of connections: 8 Way, 4 Way 1 Hop and 4 Way 2 Hops. In an 8 Way connection the connected blocks can be placed next to each other (left, right, top and bottom) and in the four corners (topleft diagonal, top-right diagonal, bottom-left diagonal, bottomright diagonal). There can be no diagonal connection in 4 Way 1 Hop. The blocks that are connected can be placed next to each other (left, right, top and bottom) or can skip one grid space in any of the four directions. 4 Way 2 Hops is like 4 Way 1 Hop connection but differs in the number of grid spaces that can be skipped which is up to two in any of the four directions. The different connection patterns are shown in Figure 2.

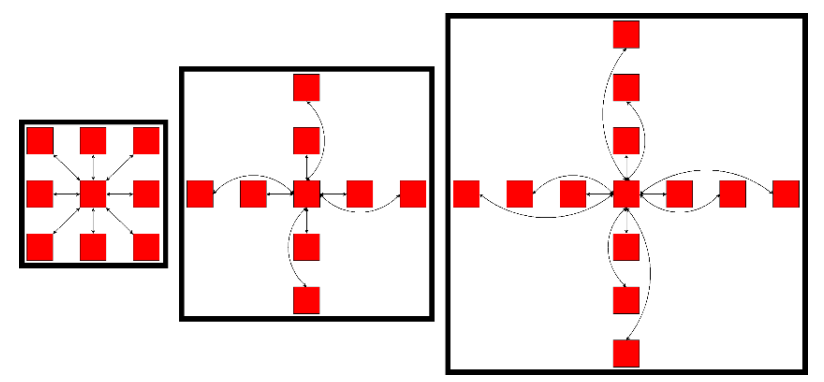

Figure 2 - Interconnect patterns used in UNTANGLED III. Left to right: 8 Way, 4 Way 1 Hop, 4 Way 2 Hops

\section{B. SET $-I I$}

The puzzles in this set come with a blue-colored circular block in addition to the red square blocks found in SET - I. A violation occurs when these circular blocks are placed at a position other than the perimeter of the gaming grid. Just like SET - I, SET - II puzzles also support the connection patterns shown in Figure 2.

\section{SET - III}

Set - III contains heterogeneous puzzles. This means not all the blocks are similar. This set contains a teal-colored square block in addition to the blocks found in SET -I. The teal-colored blocks have to be placed in the dedicated, tealcolored cells. Unlike SET - I and SET - II, SET - III puzzles support only 4 Way 1 Hop and 4 Way 2 Hops connections.

\section{D. $S E T-I V$}

Set - IV is also an implementation of the heterogeneous puzzle that takes into account all the properties of the aforementioned sets. This implies that it contains the circular blue colored blocks to be placed around the perimeter, circular, teal-colored blocks that goes in the teal-colored cells around the perimeter, the square-shaped teal-colored blocks that can be placed in any of the teal-colored cells and finally the square shaped red blocks that can be placed in any cells other than the special cells. In terms of the connection between the blocks, SET - IV supports similar connections like SET III.
The levels in the sets are arranged according to the increasing order of difficulty. In SET - I and SET - II the number of blocks is in the range 23 to 42 and the connections are in the range of 22 to 52. The same for SET - III and SET IV ranges from 21 to 42 and 20 to 52 respectively as shown in Table 1.

Table 1 - Number of Blocks and Connections in the various sets of the game

\begin{tabular}{|c|c|c|c|c|}
\hline & \multicolumn{2}{|c|}{ SET I and SET III } & \multicolumn{2}{c|}{ SET III and SET IV } \\
\hline Levels & Blocks & Connections & Blocks & $\begin{array}{c}\text { Connection } \\
\text { S }\end{array}$ \\
\hline P1 & 23 & 22 & 21 & 20 \\
\hline P2 & 28 & 30 & 23 & 22 \\
\hline P3 & 36 & 40 & 28 & 30 \\
\hline P4 & 34 & 47 & 42 & 52 \\
\hline P5 & 42 & 52 & 42 & 52 \\
\hline
\end{tabular}

In each of these sets, red or white-colored lines represent the connection between the blocks. If the color is red, then it implies a violation that the player must resolve. When the connection violation is resolved, the color of the line representing the connection becomes white. The combination of set and connectivity is most commonly known as the architectural style.

\section{DATA COLLECTION}

UNTANGLED III has been hosted on world wide web to ensure widespread availability of the game to players. The Institutional Review Board (IRB) of the institution has approved the study presented in this paper and all the necessary IRB protocols were followed wherever needed. The demographic information of the participants was collected and based on that, the participants were broadly classified into different demographic groups like age, gender, and educational background (STEM and Non-STEM). The players falling under each of these demographic groups are shown in Figures 3, 4 and 5 respectively.

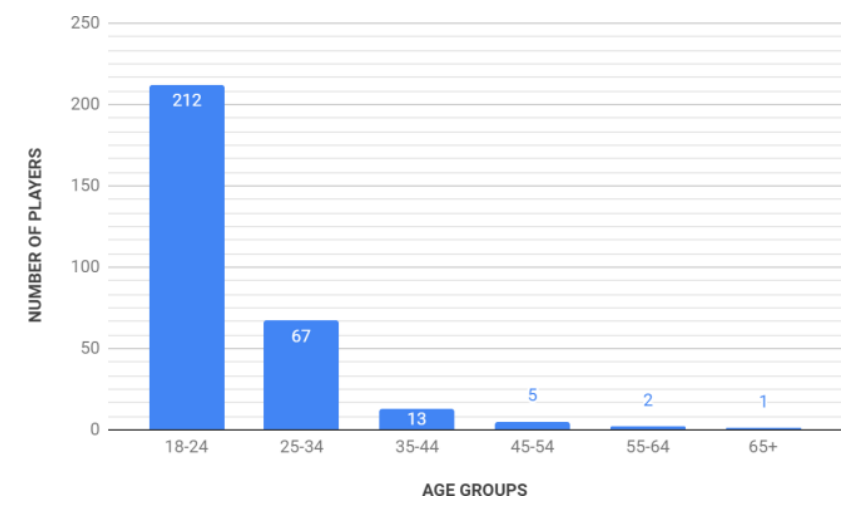

Figure 3 - Number of players from different age groups 


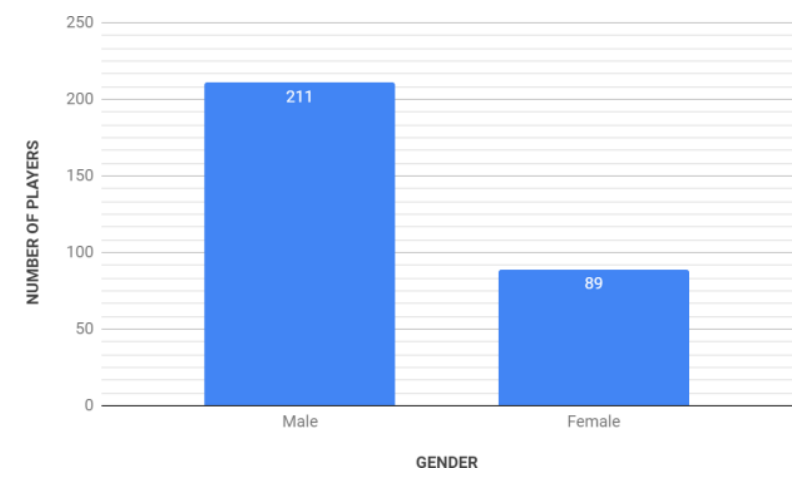

Figure 4 - Number of males and females

It is evident from Figure 5 that the participation was mainly from players with a STEM background. We have decided to improve the interface of the gaming framework in such a way that it would attract any new player and present the difficult puzzles in an appealing way so that number of participations from players irrespective of their educational background is increased. In addition to that, the scope of advertisement will also be broadened for the same cause. In terms of the age, players in the age range of 18 to 24 and 25 to 34 were seen to be taking more part in the game than players of other ranges (see Figure 3 ). In a report put forward by the Hamilton Project, 18 to 24 and 25 to 30 is the typical age range of a person attending a university. Higher participation of males in the game as seen from Figure 4 corroborates the observations already discussed in the Introduction and Background section.

\section{DATA ANALYSIS}

Existing works speak predominantly about the greater male participation in STEM-related activities. There are some studies that talks about males being better in STEM-related activities. The gameplay data of UNTANGLED III also showed higher male participation. An effort was made to compare the performance of both the genders in this game in terms of their solution of the puzzles. The following facets of the data were specifically interpreted:

(1) Moves: The aim of the players is to arrange the blocks in the puzzle in a compact space keeping into consideration all necessary architectural constraints for the different sets as mentioned before. Arranging the blocks, therefore, involves moving the blocks from one location to another. We were interested in seeing whether males and females use similar kind of moves to play the game. UNTANGLED III supports the following kinds of moves:

a. Single Move: Players can drag a block from one location to another within the gaming grid or to any location defined outside the boundary of the gaming grid when the grid dynamically resizes.

b. Multi Move: Instead of a single block, players can select multiple blocks and per- form the drag operation on that group of blocks as a unit. Just like single moves, the new location of the group of blocks selected can be within the gaming grid or to any location defined outside the boundary of the gaming grid when the grid dynamically resizes.

c. Swap Move: Swap move helps the player to drag a block on top of another block and consequently both the blocks exchange their positions.

d. Rotate Move: Players also can select a group of blocks and rotate them if required for their gameplay.

e. Pass Gate Addition/Removal: Sometimes the violations can be resolved by introducing a special block called the pass gate that functions only as a routing block be- tween two blocks. Addition of pass gates increases the area of the solution and the power requirement and hence must be done judiciously by the player.

(2) Order of Gameplay: A player can choose any level any time and the levels do not present themselves in increasing order of difficulty. The data gave an insight into the difficulty level of the puzzles chosen by the males as well as females. Did they choose the easier puzzles in the beginning and then the difficult ones or vice versa or was the choice completely random?

(3) Patterns: The detailed gameplay data also gave us some insights about the visual perception capability of the players. It was observed that players arrange some blocks in a specific pattern that led them to a solution. The gameplay data also gave us information about how the males and females have identified the patterns and how that helped them to find a solution of the puzzles.

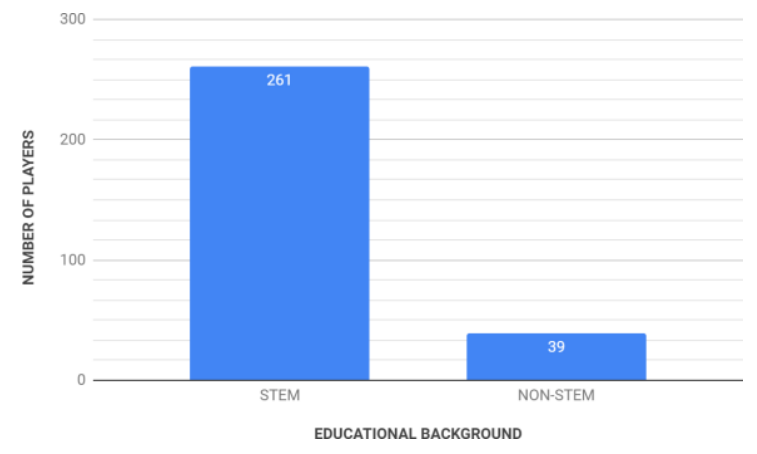

Figure 5 - Numbers of players from STEM and NonSTEM

(4) Strategy: It was interesting to observe whether players resorted to any specific strategies for the puzzles and the data showed that players exhibit similar gameplay strategies. Studying the strategies performed by the players from both genders was, therefore, another important aspect that was addressed in this paper. 


\section{A. Types of Moves performed during the Gameplay}

The different moves that a player can perform in the game UNTANGLED III have already been dis- cussed earlier. However, single and swap moves were the most predominant of all the five different moves within both the genders as observed in Figures 6 and 7.

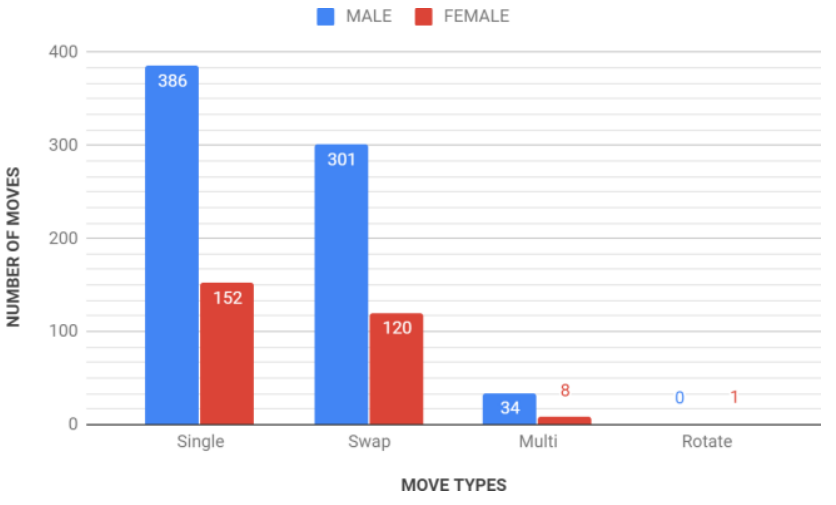

Figure 6 - Numbers of different Moves performed by players of both genders

\section{B. Order of Gameplay}

One of the characteristic features of the UNTANGLED III gaming framework is allowing the players to choose any puzzles from its wide variety of puzzles without the necessity to follow any specific order. This means the puzzles can be chosen in random and as per their desire. We were interested in observing the order in which the males and the females choose the puzzles and whether such a choice had an impact on their performance.

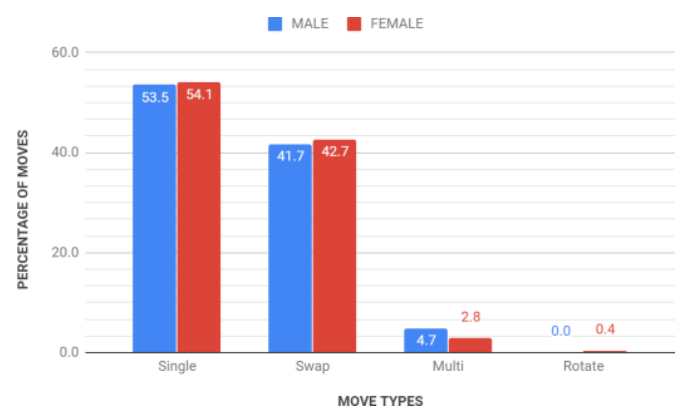

Figure 7 - Percentage of different Moves performed by players of both genders

Figures 8, 9, 10 and 11 show the puzzles that players from both genders have played as their initial and final attempt. Table 2 describes the legends in the horizontal axis. For example, 4W2H-S3-P1 means the puzzle 1 taken from fourway two hops, SET - III. These figures help to get an insight into whether the players are attempting the easier puzzles initially or choosing any level in random. It also helps to find out the exact puzzles that players from both backgrounds have played as their initial attempt and final attempt.

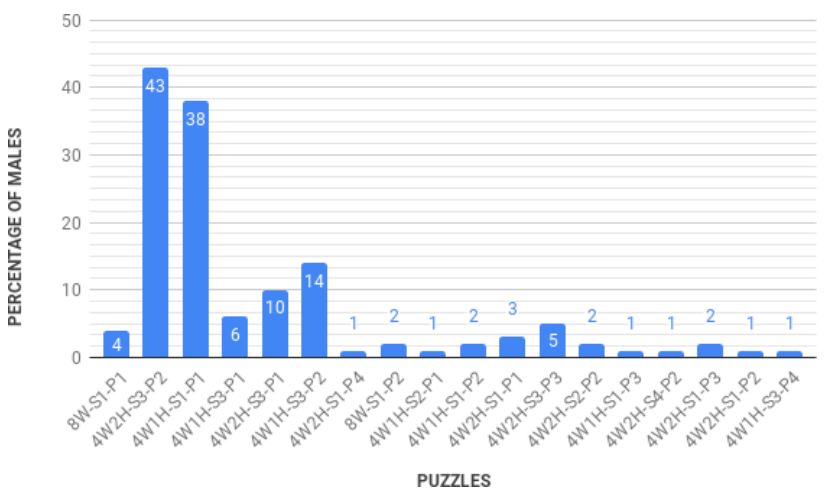

Figure 8 - Males - Initial attempt

It is evident that 4 Way 1 Hop - SET - I and 4 Way 2 Hops - SET - III puzzles are the most popular among the players. In terms of variation in the gameplay, males showed a wider variation in the selection of puzzles over females. Besides 4 Way 1 Hop - SET - I, males also played 4 Way 2 Hops - SET III puzzles which the females did not in their initial attempt. The variation in the puzzles chosen by the males as their initial attempt is also much more varied than that of the females. A similar picture is observed when the final attempts of the players were taken into account. There were some puzzles that were, however, attempted by both the genders.

Table 2 - Keyword descriptions

\begin{tabular}{|c|c|}
\hline Keyword & Meaning \\
\hline P1 through P5 & Puzzle 1 through Puzzle 5 \\
\hline 4W & Four Way \\
\hline 8W & Eight Way \\
\hline S1 through S4 & SET - I through SET - IV \\
\hline 1H & One Hop \\
\hline 2H & Two Hop \\
\hline
\end{tabular}

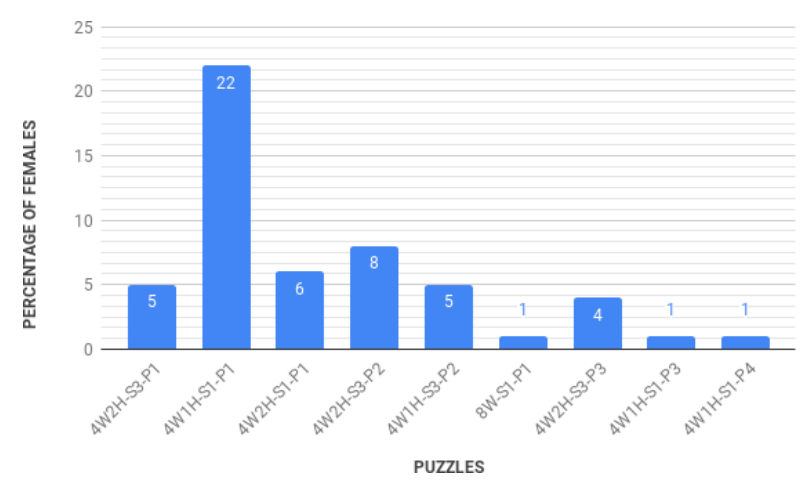

Figure 9 - Females - Initial attempt 


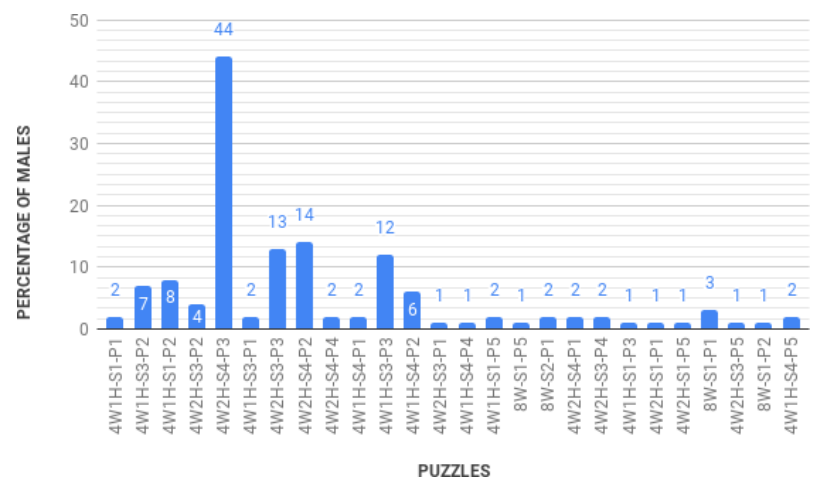

Figure 10 - Males - Final attempt

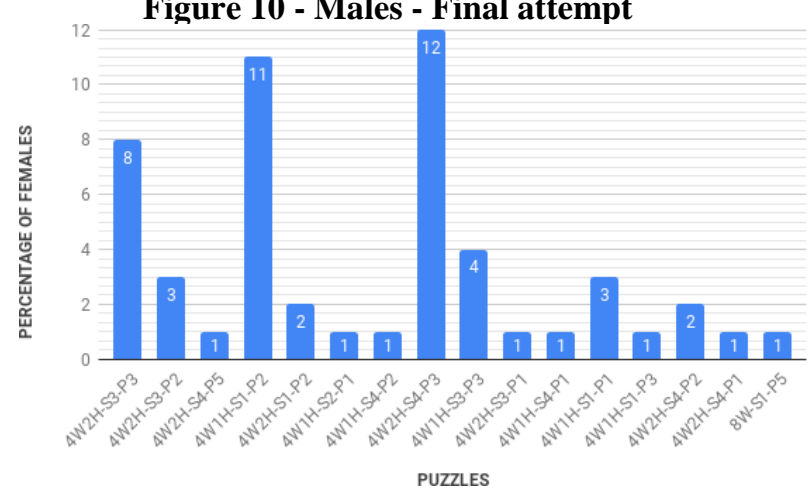

Figure 11 - Females - Final attempt

Apart from the wider variation in the selection of the puzzles, it can be inferred that females and males had no strategic gameplay order. Females were, however, systematic and showed a tendency to start with the easier puzzles and then attempt the difficult puzzles.

\section{Patterns observed in the game}

Players have a tendency to arrange blocks in different patterns when subjected to an arrangement problem [20]. The patterns observed in the solutions of the players in UNTANGLED III are shown in Figure 12. The colored blocks represent nodes or the blocks in the DFGs used in the puzzles and the thick black lines represent the connections between the blocks. The numbers near the connections is indicative of the hop the connection makes between the blocks.

It is seen from Figures 13 and 14 that both males and females predominantly showed a tendency to arrange the blocks to form vertical and horizontal chains.
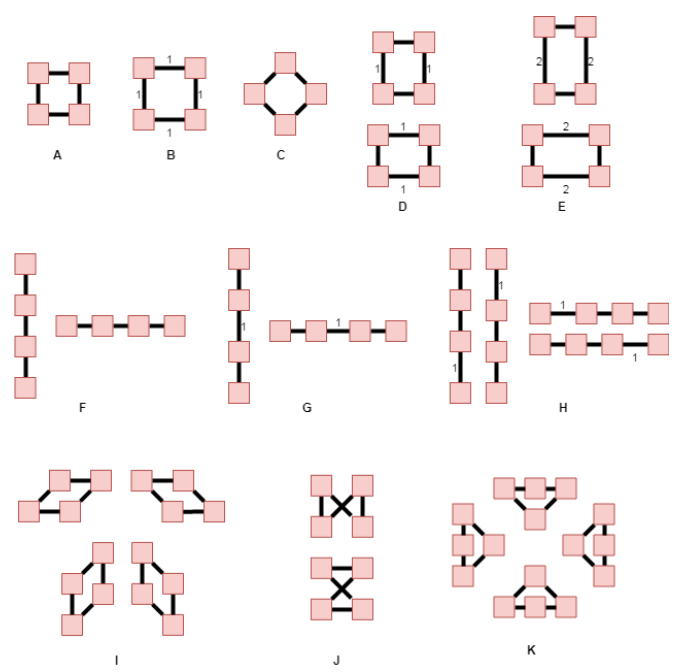

Figure 12 - Various patterns observed in the solution of the players

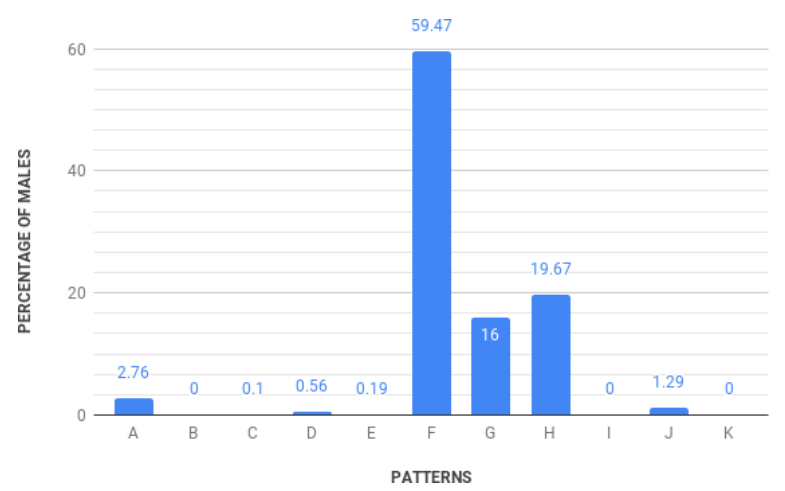

Figure 13 - Percentage of various patterns in the solutions of Males

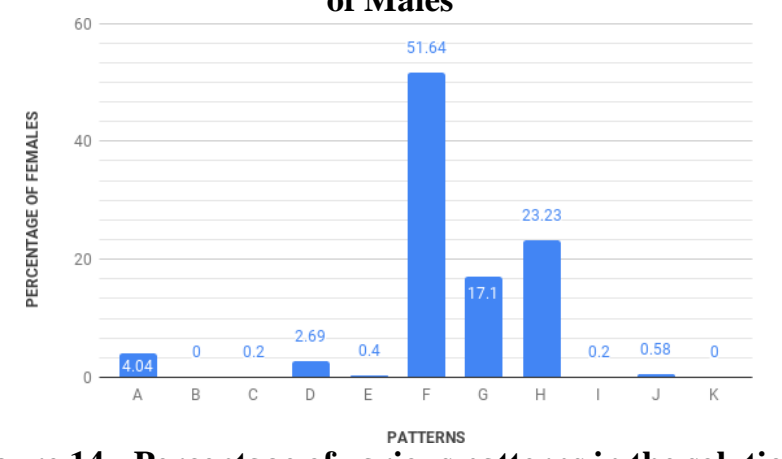

Figure 14 - Percentage of various patterns in the solutions of Females

D. Strategies used in the game

A detailed analysis of the gameplay differences and similarities between males and the females require probing into more details. This subsection aims to address the following questions:

- What kinds of moves did the males and the females use to get a solution to the puzzles?

- Did the players use similar strategy throughout their gameplay sessions? 
- Did the players change their strategies for difficult puzzles?

There are some trends in the strategies of the players that were observed, and they are discussed below:

- $\quad$ Players from both genders used only the single and swap moves. For simple puzzles, the players predominantly used single moves to get to their final solution. This means that players from both genders felt convenient to play the puzzle by moving one block at a time. Swap moves were performed only when the players were convinced that swapping would reduce the number of red wires in their solution and lead to an increase in the score. Both the males and the females redid a swap move on the same pair of blocks which were swapped before. This strategy was however very random. Figures 15 and 16 show that single moves were more common among the players irrespective of their gender. The description of the keywords used in the vertical axis of Figures 15 and 16 is mentioned in Table 2. For example, $4 \mathrm{~W} 1 \mathrm{H}-\mathrm{S} 1, \mathrm{P} 1$ means the puzzle 1 taken from four-way one hop, SET - I.

- $\quad$ Players irrespective of gender tend to start playing a puzzle by first concentrating upon a block that was positioned in one edge. They took care of the other connecting blocks and arranged them to get a feasible solution. On many occasions, players moved the blocks towards a region that had a lesser number of violations and built a solution from there. Figure 17 shows how a player moved the blocks on the left side where there was lesser number of violations and arranged the blocks there to resolve the violations.

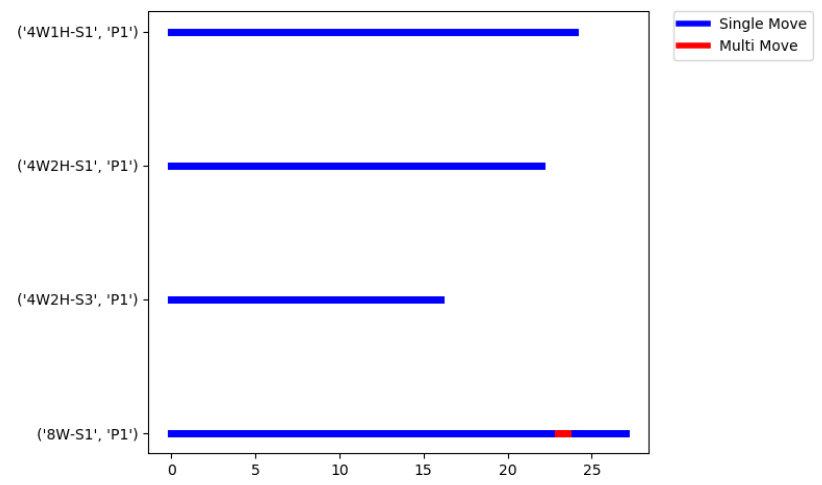

Figure 15 - Dominance of Single moves in the solutions of Males

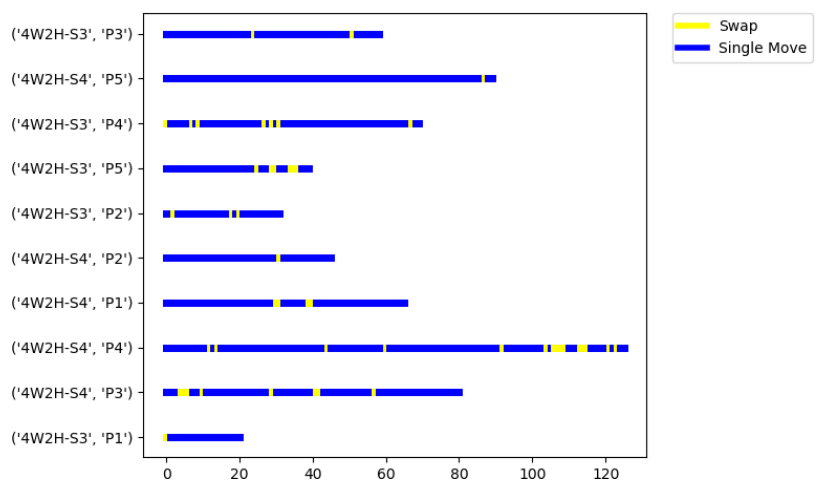

Figure 16 - Dominance of Single moves in the solutions of Females

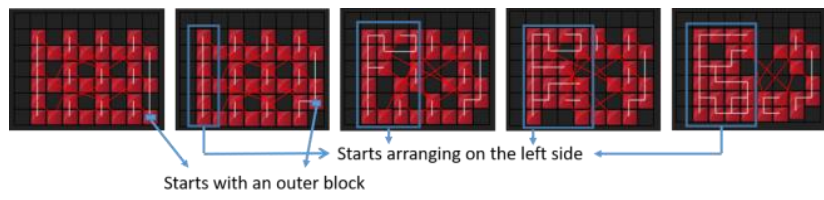

Figure 17 - A Player starting with an outer block and then focusing on the left side

- Both genders also showed similar strategies when they played difficult puzzles. For example, when they played the puzzles containing the special blocks, two different strategies were observed. Some players took care of the special blocks in the beginning and placed them in their respective cells. Once the special blocks were placed in their respective cells, they turned their attention into arranging the ordinary blocks in the puzzle that were directly connected to the special blocks. The other strategy prevalent among the males as well as the females was to take care of the ordinary blocks first and then place the special blocks in their proper cells. There are however some players who followed none of the strategies. Such players showed very random moves and performed a greater number of moves to obtain a final solution than the players who followed a strategy.

- $\quad$ For SET - IV of the game, players from both genders showed similar strategies too. In this set players placed the circular blue colored blocks in their corresponding cells and built their solution around that. They did not move these special blocks to any other place in the gaming grid. They perform a lot of moves on the ordinary blocks and the square-shaped, teal-colored blocks to resolve the violations that the set offers. Figures 18 through 21 provide a comparative representation of two players and the number of various moves they performed on various blocks, respectively. 


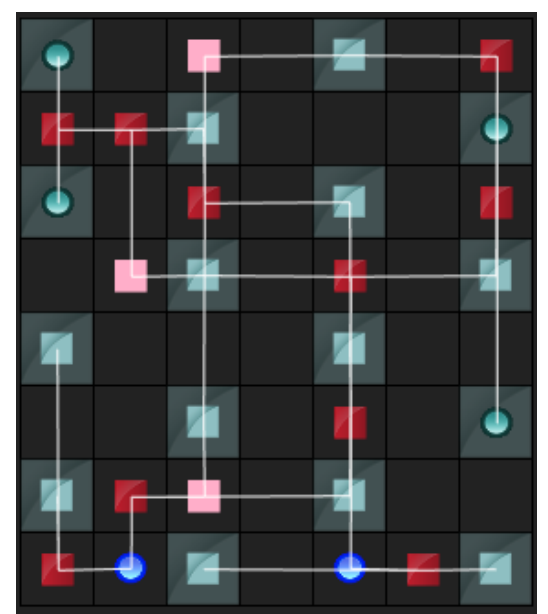

Figure 18 - Player 1, SET - IV final solution

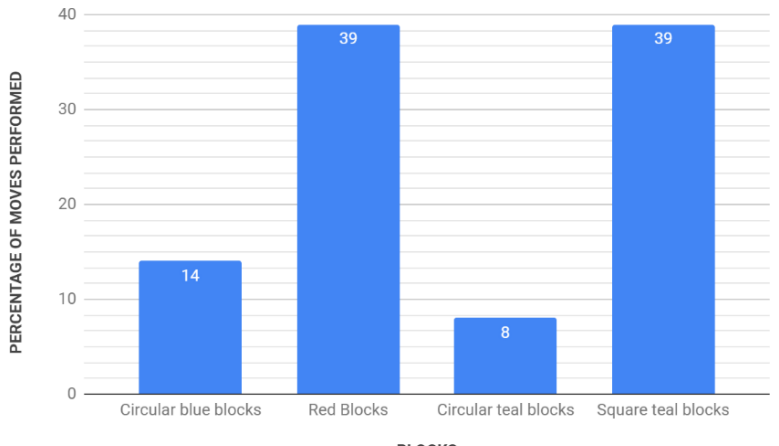

Figure 19 - Player 1, SET - IV percentage of moves performed on various blocks

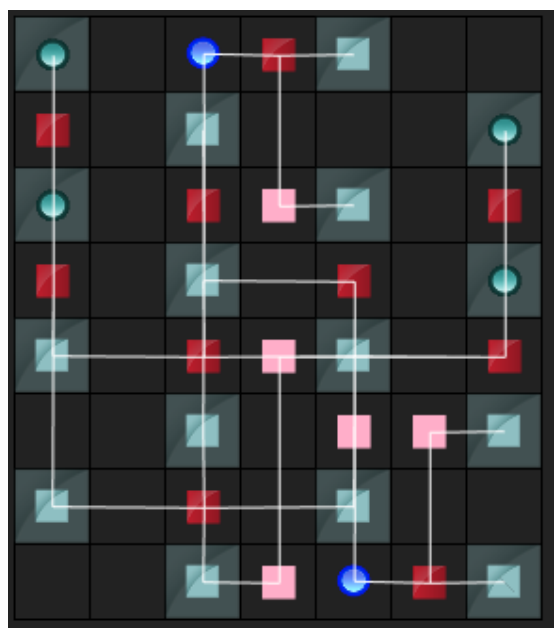

Figure 20 - Player 2, SET - IV final solution

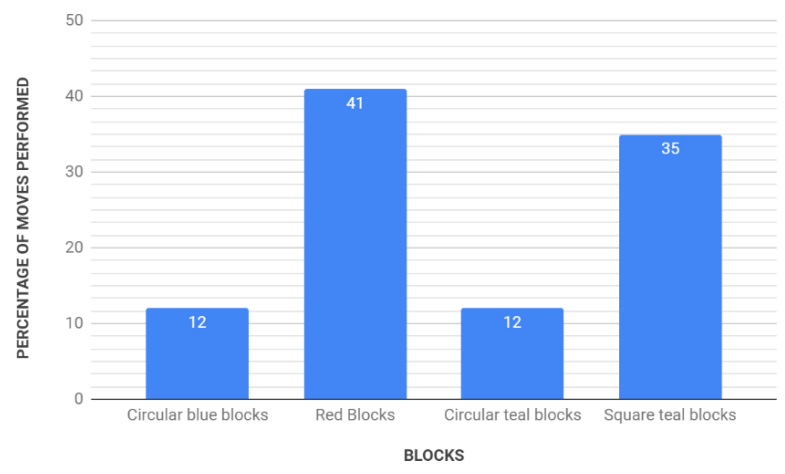

Figure 21 - Player 2, SET - IV percentage of moves performed on various blocks

\section{Statistical ANALYSIS Of GAMEPLAy DATA}

\section{A. Male and Female Participation}

Puzzles with more participation have been considered to evaluate the percentage of the males and females in each of the puzzles as shown in Figure 22. The percentage of male players is more compared to the percentage of female players in all six architectures (consult Table 2 for the keywords). With the increase in puzzle difficulty, male participation shows a slight tendency to increase. Whereas, in the case of females the trend is in the opposite side.

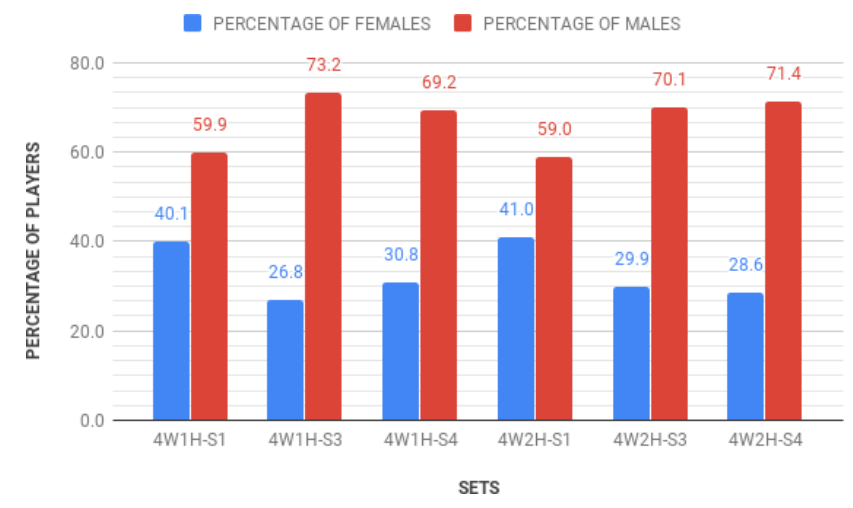

Figure 22 - Percentage of Male and Female players in different sets of the game

Table 3 - Percentage of Male and Female players in 4W1H-S1 and

\begin{tabular}{|c|c|c|c|c|c|c|}
\multicolumn{7}{|c|}{ 4W2H-S1 (P1-P5 puzzles) } \\
\hline \multirow{2}{*}{ Architecture } & & \multicolumn{5}{|c|}{ Levels } \\
\hline \multirow{2}{*}{$4 \mathrm{~W} 1 \mathrm{H}-\mathrm{S} 1$} & $\mathrm{~F}$ & $37.3 \%$ & $43.9 \%$ & $41.7 \%$ & $50.0 \%$ & $40.0 \%$ \\
\cline { 2 - 7 } & $\mathrm{M}$ & $62.7 \%$ & $56.1 \%$ & $58.3 \%$ & $50.0 \%$ & $60.0 \%$ \\
\hline \multirow{2}{*}{$4 \mathrm{~W} 2 \mathrm{H}-\mathrm{S} 1$} & $\mathrm{~F}$ & $35.0 \%$ & $50.0 \%$ & $25.0 \%$ & $75.0 \%$ & $33.3 \%$ \\
\cline { 2 - 7 } & $\mathrm{M}$ & $65.0 \%$ & $50.0 \%$ & $75.0 \%$ & $25.0 \%$ & $66.7 \%$ \\
\hline
\end{tabular}

Table 4 - Percentage of Male and Female players in 4W1H-S3 and 4W2H-S3 (P1-P5 puzzles)

\begin{tabular}{|c|c|c|c|c|c|c|}
\hline & & \multicolumn{5}{|c|}{ Levels } \\
\hline Architecture & Gender & P1 & P2 & P3 & P4 & P5 \\
\hline \multirow{2}{*}{$4 \mathrm{~W} 1 \mathrm{H}-\mathrm{S} 3$} & $\mathrm{~F}$ & $20.8 \%$ & $24.7 \%$ & $35.3 \%$ & $66.7 \%$ & $50.0 \%$ \\
\cline { 2 - 7 } & $\mathrm{M}$ & $79.2 \%$ & $75.3 \%$ & $64.7 \%$ & $33.3 \%$ & $50.0 \%$ \\
\hline
\end{tabular}




\begin{tabular}{|c|c|c|c|c|c|c|}
\hline \multirow{2}{*}{ 4W2H-S3 } & $\mathrm{F}$ & $42.2 \%$ & $26.1 \%$ & $24.5 \%$ & $66.7 \%$ & $60.0 \%$ \\
\cline { 2 - 7 } & $\mathrm{M}$ & $57.8 \%$ & $73.9 \%$ & $75.5 \%$ & $33.3 \%$ & $40.0 \%$ \\
\hline
\end{tabular}

Table 5 - Percentage of Male and Female players in 4W1H-S4 and 4W2H-S4 (P1-P5 puzzles)

\begin{tabular}{|c|c|c|c|c|c|c|}
\hline & & \multicolumn{5}{|c|}{ LWevels } \\
\hline Architecture & Gender & P1 & P2 & P3 & P4 & P5 \\
\hline \multirow{2}{*}{4 W1H-S4 } & F & $45.5 \%$ & $22.2 \%$ & $25.0 \%$ & $33.3 \%$ & $33.3 \%$ \\
\cline { 2 - 7 } & $\mathrm{M}$ & $54.5 \%$ & $77.8 \%$ & $75.0 \%$ & $66.7 \%$ & $66.7 \%$ \\
\hline \multirow{2}{*}{4 W2H-S4 } & $\mathrm{F}$ & $50.0 \%$ & $21.6 \%$ & $26.2 \%$ & $50.0 \%$ & $66.7 \%$ \\
\cline { 2 - 7 } & $\mathrm{M}$ & $50.0 \%$ & $78.4 \%$ & $73.8 \%$ & $50.0 \%$ & $33.3 \%$ \\
\hline
\end{tabular}

Tables 3, 4 and 5 show the percentage of players who played P1-P5 puzzles in 4W1H-S1, 4W2H- S1, 4W1H-S3, 4W2H-S3, 4W1H-S4 and 4W2H-S4 architectures. In P4 and P5 puzzles of 4W2H - Set - I, 4W2H - Set - III and 4W2H - Set - IV architectures, female participants are more compared to male participants.

\section{B. Move Analysis}

The dominance of single and swap moves in this game in the solutions of the players, irrespective of the gender has already been established before. An exploratory analysis of the observed data revealed that the data is not normally distributed. Hence, the one-way ANOVA on ranks test, which is a non-distributed test on the data for puzzles was performed that showed larger participation for both genders.

To perform this test, Gender (Female and Male) has been considered as an independent variable and single, swap and total moves as dependent variables. Asymptotic significance value (mentioned as Asymp. Sig. in Tables 7, 9 and 11) which is also known as the p-value represents the statistically significant difference between the groups (Male and Female). If the $p 0.05$, there is a statistically significant difference within the groups (Female and Male), whereas if $p>0.05$, there is no significant difference between the groups (Female and Male). The significance values on Tables 7, 9 and 11, conclude that there is no significant difference between total moves and the number of single and swap moves used by the Female and Male players. Tables 6, 8 and 10 show mean ranks for Female and Male groups for each dependent variable. For instance, in Table 6 we can see that mean ranks for Female (10.00) and Male (10.77) shows that mean number of single moves used by the Male is more compared to Female players. In addition, we can see that mean ranks of swap moves for Male and Female are 12.00 and 9.69. This shows that mean number of swap moves used by Female is more compared to Male players. Hence, Table 6 concludes that mean number of swap moves used by Female players is more than Male players in puzzles P1-P5. Tables 6, 8 and 10 depict that mean ranks of dependent variables i.e., single, swap and total moves for Female and Male groups are almost equal in almost all cases.
Table 6 - Mean Ranks calculated for independent variable based on dependent variables $4 \mathrm{~W} 2 \mathrm{H}$ -

\begin{tabular}{|c|c|c|c|c|c|c|c|c|c|}
\hline \multicolumn{10}{|c|}{ S1 (P1-P5 puzzles) } \\
\hline \multicolumn{10}{|c|}{ Mean Ranks for 4W2H-S1 } \\
\hline \multicolumn{2}{|c|}{ Puzzles } & \multirow{2}{*}{$\begin{array}{l}\text { Gender } \\
\text { Female }\end{array}$} & \multirow[t]{2}{*}{$\mathbf{N}$} & \multirow{2}{*}{$\begin{array}{r}\text { Mean } \\
\text { Rank }\end{array}$} & \multicolumn{2}{|c|}{ Puzzles } & \multirow{2}{*}{$\begin{array}{l}\text { Gender } \\
\text { Female }\end{array}$} & \multirow{2}{*}{$\begin{array}{l}\mathbf{N} \\
4 \\
\end{array}$} & \multirow{2}{*}{$\begin{array}{r}\text { Mean } \\
\text { Rank }\end{array}$} \\
\hline \multirow{9}{*}{ P1 } & \multirow{3}{*}{ Single } & & & & \multirow{9}{*}{ P2 } & \multirow{3}{*}{ Single } & & & \\
\hline & & Male & 13 & 10.77 & & & Male & 4 & 4.75 \\
\hline & & Total & 20 & & & & Total & 8 & \\
\hline & \multirow{3}{*}{ Swap } & Female & 7 & 12.00 & & \multirow{3}{*}{ Swap } & Female & 4 & 5.38 \\
\hline & & Male & 13 & 9.69 & & & Male & 4 & 3.63 \\
\hline & & Total & 20 & & & & Total & 8 & \\
\hline & \multirow{3}{*}{$\begin{array}{r}\text { Total } \\
\text { Moves }\end{array}$} & Female & 7 & 11.00 & & \multirow{3}{*}{$\begin{array}{r}\text { Total } \\
\text { Moves }\end{array}$} & Female & 4 & 4.50 \\
\hline & & Male & 13 & 10.23 & & & Male & 4 & 4.50 \\
\hline & & Total & 20 & & & & Total & 8 & \\
\hline \multirow{9}{*}{ P3 } & \multirow{3}{*}{ Single } & Female & 1 & 2.00 & \multirow{9}{*}{ P4 } & \multirow{3}{*}{ Single } & Female & 3 & 2.33 \\
\hline & & Male & 3 & 2.67 & & & Male & 1 & 3.00 \\
\hline & & Total & 4 & & & & Total & 4 & \\
\hline & \multirow{3}{*}{ Swap } & Female & 1 & 3.00 & & \multirow{3}{*}{ Swap } & Female & 3 & 2.67 \\
\hline & & Male & 3 & 2.33 & & & Male & 1 & 2.00 \\
\hline & & Total & 4 & & & & Total & 4 & \\
\hline & \multirow{3}{*}{$\begin{array}{r}\text { Total } \\
\text { Moves }\end{array}$} & Female & 1 & 2.00 & & \multirow{3}{*}{$\begin{array}{r}\text { Total } \\
\text { Moves }\end{array}$} & Female & 3 & 2.33 \\
\hline & & Male & 3 & 2.67 & & & Male & 1 & 3.00 \\
\hline & & Total & 4 & & & & Total & 4 & \\
\hline \multirow{9}{*}{ P5 } & \multirow{3}{*}{ Single } & Female & 1 & 3.00 & & & & & \\
\hline & & Male & 2 & 1.50 & & & & & \\
\hline & & Total & 3 & & & & & & \\
\hline & \multirow{3}{*}{ Swap } & Female & 1 & 3.00 & & & & & \\
\hline & & Male & 2 & 1.50 & & & & & \\
\hline & & Total & 3 & & & & & & \\
\hline & Total & Female & 1 & 3.00 & & & & & \\
\hline & Moves & Male & 2 & 1.50 & & & & & \\
\hline & & Total & 3 & & & & & & \\
\hline
\end{tabular}

Table 7 - Significance level of dependent variables between Male and Female groups 4W2H-S1 (P1-P5 puzzles)

\begin{tabular}{|c|c|c|c|c|}
\hline \multicolumn{5}{|c|}{ Test Statistics } \\
\hline Levels & & Single & Swap & $\begin{array}{l}\text { Total } \\
\text { Moves }\end{array}$ \\
\hline \multirow{3}{*}{ P1 } & Chi-Square & 0.077 & 0.957 & 0.077 \\
\hline & df & 1.000 & 1.000 & 1.000 \\
\hline & Asymp. Sig. & 0.781 & 0.328 & 0.781 \\
\hline \multirow{3}{*}{$\mathrm{P} 2$} & Chi-Square & 0.083 & 1.085 & 0.000 \\
\hline & df & 1.000 & 1.000 & 1.000 \\
\hline & Asymp. Sig. & 0.773 & 0.297 & 1.000 \\
\hline \multirow{3}{*}{ P3 } & Chi-Square & 0.200 & 0.200 & 0.200 \\
\hline & df & 1.000 & 1.000 & 1.000 \\
\hline & Asymp. Sig. & 0.655 & 0.655 & 0.655 \\
\hline \multirow{3}{*}{ P4 } & Chi-Square & 0.200 & 0.200 & 0.200 \\
\hline & df & 1.000 & 1.000 & 1.000 \\
\hline & Asymp. Sig. & 0.655 & 0.655 & 0.655 \\
\hline \multirow{3}{*}{ P5 } & Chi-Square & 1.500 & 1.500 & 1.500 \\
\hline & df & 1.000 & 1.000 & 1.000 \\
\hline & Asymp. Sig. & 0.221 & 0.221 & 0.221 \\
\hline
\end{tabular}


Table 8 - Mean Ranks calculated for independent variable based on dependent variables $4 \mathrm{~W} 2 \mathrm{H}$ S3 (P1-P5 puzzles)

\begin{tabular}{|c|c|c|c|c|c|c|c|c|c|}
\hline \multicolumn{10}{|c|}{ Mean Ranks for $4 \mathrm{~W} 2 \mathrm{H}-\mathrm{S} 1$} \\
\hline \multicolumn{2}{|c|}{ Puzzles } & \multirow{2}{*}{$\begin{array}{l}\text { Gender } \\
\text { Female }\end{array}$} & \multirow{2}{*}{$\begin{array}{l}\mathbf{N} \\
19\end{array}$} & \multirow{2}{*}{$\begin{array}{r}\begin{array}{r}\text { Mean } \\
\text { Rank }\end{array} \\
24.37\end{array}$} & \multicolumn{2}{|c|}{ Puzzles } & \multirow{2}{*}{$\begin{array}{l}\text { Gender } \\
\text { Female }\end{array}$} & \multirow{2}{*}{\begin{tabular}{|l|}
$\mathbf{N}$ \\
29 \\
\end{tabular}} & \multirow{2}{*}{$\begin{array}{c}\text { Mean } \\
\text { Rank }\end{array}$} \\
\hline \multirow{9}{*}{ P1 } & \multirow{3}{*}{ Single } & & & & & \multirow{3}{*}{ Single } & & & \\
\hline & & Male & 26 & 22 & & & Male & 82 & 56.80 \\
\hline & & Total & 45 & & P2 & & Total & 111 & \\
\hline & \multirow{3}{*}{ Swap } & Female & 19 & 25.26 & & \multirow{3}{*}{ Swap } & Female & 29 & 51.40 \\
\hline & & Male & 26 & 21.35 & & & Male & 82 & 57.63 \\
\hline & & Total & 45 & & & & Total & 111 & \\
\hline & \multirow{3}{*}{$\begin{array}{r}\text { Total } \\
\text { Moves }\end{array}$} & Female & 19 & 24.61 & & \multirow{3}{*}{$\begin{array}{r}\text { Total } \\
\text { Moves }\end{array}$} & Female & 29 & 52.14 \\
\hline & & Male & 26 & 21.83 & & & Male & 82 & 57.37 \\
\hline & & Total & 45 & & & & Total & 111 & \\
\hline \multirow{9}{*}{ P3 } & \multirow{3}{*}{ Single } & Female & 23 & 47.30 & & \multirow{3}{*}{ Single } & Female & 4 & 3.25 \\
\hline & & Male & 71 & 47.56 & & & Male & 2 & 4.00 \\
\hline & & Total & 94 & & P4 & & Total & 6 & \\
\hline & \multirow{3}{*}{ Swap } & Female & 23 & 49.52 & & \multirow{3}{*}{ Swap } & Female & 4 & 3.38 \\
\hline & & Male & 71 & 46.85 & & & Male & 2 & 3.75 \\
\hline & & Total & 94 & & & & Total & 6 & \\
\hline & \multirow{3}{*}{$\begin{array}{r}\text { Total } \\
\text { Moves }\end{array}$} & Female & 23 & 46.93 & & \multirow{3}{*}{$\begin{array}{r}\text { Total } \\
\text { Moves }\end{array}$} & Female & 4 & 3.25 \\
\hline & & Male & 71 & 47.68 & & & Male & 2 & 4.00 \\
\hline & & Total & 94 & & & & Total & 6 & \\
\hline \multirow{9}{*}{ P5 } & \multirow[t]{3}{*}{ Single } & Female & 3 & 3.00 & & & & & \\
\hline & & Male & 2 & 3.00 & & & & & \\
\hline & & Total & 5 & & & & & & \\
\hline & \multirow{3}{*}{ Swap } & Female & 3 & 3.67 & & & & & \\
\hline & & Male & 2 & 2.00 & & & & & \\
\hline & & Total & 5 & & & & & & \\
\hline & \multirow{3}{*}{$\begin{array}{r}\text { Total } \\
\text { Moves }\end{array}$} & Female & 3 & 3.00 & & & & & \\
\hline & & Male & 2 & 3.00 & & & & & \\
\hline & & Total & 5 & & & & & & \\
\hline
\end{tabular}

Table 9 - Significance level of dependent variables between Male and Female groups 4W2H-S3

\begin{tabular}{|c|c|c|c|c|}
\hline \multicolumn{5}{|c|}{ Test Statistics } \\
\hline \multirow{3}{*}{ Levels } & & Single & Swap & $\begin{array}{c}\text { Total } \\
\text { Moves }\end{array}$ \\
\hline \multirow{3}{*}{ P1 } & Chi-Square & 0.357 & 1.181 & 0.491 \\
\cline { 2 - 5 } & df & 1.000 & 1.000 & 1.000 \\
\cline { 2 - 5 } & Asymp. Sig. & 0.550 & 0.277 & 0.483 \\
\hline \multirow{3}{*}{ P2 } & Chi-Square & 0.193 & 0.815 & 0.565 \\
\cline { 2 - 5 } & df & 1.000 & 1.000 & 1.000 \\
\cline { 2 - 5 } & Asymp. Sig. & 0.660 & 0.367 & 0.452 \\
\hline \multirow{3}{*}{ P3 } & Chi-Square & 0.002 & 0.169 & 0.013 \\
\cline { 2 - 5 } & df & 1.000 & 1.000 & 1.000 \\
\cline { 2 - 5 } & Asymp. Sig. & 0.968 & 0.681 & 0.909 \\
\hline \multirow{3}{*}{ P4 } & Chi-Square & 0.221 & 0.055 & 0.214 \\
\cline { 2 - 5 } & df & 1.000 & 1.000 & 1.000 \\
\cline { 2 - 5 } & Asymp. Sig. & 0.639 & 0.814 & 0.643 \\
\hline \multirow{3}{*}{ P5 } & Chi-Square & 0.000 & 1.333 & 0.000 \\
\cline { 2 - 5 } & df & 1.000 & 1.000 & 1.000 \\
\cline { 2 - 5 } & Asymp. Sig. & 1.000 & 0.248 & 1.000 \\
\hline
\end{tabular}

Table 10 - Mean Ranks calculated for independent variable based on dependent variables $4 \mathrm{~W} 2 \mathrm{H}$ S4 (P1-P5 puzzles)

\begin{tabular}{|c|c|c|c|c|c|c|c|c|c|}
\hline \multicolumn{10}{|c|}{ Mean Ranks for 4W2H-S1 } \\
\hline \multicolumn{2}{|c|}{ Puzzles } & \multirow{3}{*}{$\begin{array}{c}\text { Gender } \\
\text { Female } \\
\text { Male }\end{array}$} & \multirow{3}{*}{$\frac{9}{9}$} & \multirow{2}{*}{$\begin{array}{r}\begin{array}{r}\text { Mean } \\
\text { Rank }\end{array} \\
8.83\end{array}$} & \multicolumn{2}{|c|}{ Puzzles } & \multirow{2}{*}{$\begin{array}{c}\text { Gender } \\
\text { Female }\end{array}$} & \multirow{2}{*}{$\begin{array}{l}\mathbf{N} \\
19\end{array}$} & \multirow{2}{*}{$\begin{array}{c}\text { Mean } \\
\text { Rank }\end{array}$} \\
\hline \multirow{9}{*}{ P1 } & \multirow{3}{*}{ Single } & & & & & \multirow{3}{*}{ Single } & & & \\
\hline & & & & 10.17 & & & Male & 69 & 45.78 \\
\hline & & Total & 18 & & P2 & & Total & 88 & \\
\hline & \multirow{3}{*}{ Swap } & Female & 9 & 9.22 & & \multirow{3}{*}{ Swap } & Female & 19 & 39.84 \\
\hline & & Male & 9 & 9.78 & & & Male & 69 & 45.78 \\
\hline & & Total & 18 & & & & Total & 88 & \\
\hline & \multirow{3}{*}{$\begin{array}{l}\text { Total } \\
\text { Moves }\end{array}$} & Female & 9 & 8.94 & & \multirow{3}{*}{$\begin{array}{l}\text { Total } \\
\text { Moves }\end{array}$} & Female & 19 & 38.71 \\
\hline & & Male & 9 & 10.06 & & & Male & 69 & 46.09 \\
\hline & & Total & 18 & & & & Total & 88 & \\
\hline \multirow{9}{*}{ P3 } & \multirow{3}{*}{ Single } & Female & 17 & 39.53 & \multirow{9}{*}{ P4 } & \multirow{3}{*}{ Single } & Female & 4 & 3.75 \\
\hline & & Male & 48 & 30.69 & & & Male & 4 & 5.25 \\
\hline & & Total & 65 & & & & Total & 8 & \\
\hline & \multirow{3}{*}{ Swap } & Female & 17 & 37.35 & & \multirow{3}{*}{ Swap } & Female & 4 & 4.88 \\
\hline & & Male & 48 & 31.46 & & & Male & 4 & 4.13 \\
\hline & & Total & 65 & & & & Total & 8 & \\
\hline & \multirow{3}{*}{$\begin{array}{r}\text { Total } \\
\text { Moves }\end{array}$} & Female & 17 & 38.97 & & \multirow{3}{*}{$\begin{array}{l}\text { Total } \\
\text { Moves }\end{array}$} & Female & 4 & 3.75 \\
\hline & & Male & 48 & 30.89 & & & Male & 4 & 5.25 \\
\hline & & Total & 65 & & & & Total & 8 & \\
\hline \multirow{9}{*}{ P5 } & \multirow{3}{*}{ Single } & Female & 4 & 3.50 & & & & & \\
\hline & & Male & 2 & 3.50 & & & & & \\
\hline & & Total & 6 & & & & & & \\
\hline & \multirow{3}{*}{ Swap } & Female & 4 & 4.00 & & & & & \\
\hline & & Male & 2 & 2.50 & & & & & \\
\hline & & Total & 6 & & & & & & \\
\hline & \multirow{3}{*}{$\begin{array}{r}\text { Total } \\
\text { Moves }\end{array}$} & Female & 4 & 3.50 & & & & & \\
\hline & & Male & 2 & 3.50 & & & & & \\
\hline & & Total & 6 & & & & & & \\
\hline
\end{tabular}

Table 11 - Significance level of dependent variables between Male and Female groups 4W2H-S4 (P1-P5 puzzles)

\begin{tabular}{|c|c|c|c|c|}
\hline \multicolumn{5}{|c|}{ Test Statistics } \\
\hline \multirow{2}{*}{ Levels } & & Single & Swap & $\begin{array}{c}\text { Total } \\
\text { Moves }\end{array}$ \\
\hline \multirow{4}{*}{ P1 } & Chi-Square & 0.281 & 0.050 & 0.195 \\
\cline { 2 - 5 } & df & 1.000 & 1.000 & 1.000 \\
\cline { 2 - 5 } & Asymp. Sig. & 0.596 & 0.824 & 0.659 \\
\hline \multirow{4}{*}{ P2 } & Chi-Square & 0.806 & 1.276 & 0.634 \\
\cline { 2 - 5 } & df & 1.000 & 1.000 & 1.000 \\
\cline { 2 - 5 } & Asymp. Sig. & 0.369 & 0.259 & 0.426 \\
\hline \multirow{4}{*}{ P3 } & Chi-Square & 2.746 & 1.229 & 2.296 \\
\cline { 2 - 5 } & df & 1.000 & 1.000 & 1.000 \\
\cline { 2 - 5 } & Asymp. Sig. & 0.097 & 0.268 & 0.130 \\
\hline \multirow{3}{*}{ P4 } & Chi-Square & 0.750 & 0.190 & 0.750 \\
\cline { 2 - 5 } & df & 1.000 & 1.000 & 1.000 \\
\cline { 2 - 5 } & Asymp. Sig. & 0.386 & 0.663 & 0.386 \\
\hline \multirow{4}{*}{ P5 } & Chi-Square & 0.000 & 0.857 & 0.000 \\
\cline { 2 - 5 } & df & 1.000 & 1.000 & 1.000 \\
\cline { 2 - 5 } & Asymp. Sig. & 1.000 & 0.355 & 1.000 \\
\hline
\end{tabular}




\section{CONCLUSION}

The e-gaming platform has been constantly evolving. Studies show that kids spend a considerable span of time on these platforms. Based on that data, researchers have delved into developing an e-gaming framework that is fun and at the same time educational. The benefits of these e-gaming platforms have proved to be more profound in STEM disciplines. The difficult STEM concepts once incorporated into these platforms can be presented to the kids in a fun and interesting manner and make them inclined towards pursuing a STEM-based education. STEM disciplines, however, are yet to catch up with the non-STEM disciplines in terms of the number of people opting for it.

UNTANGLED III aims to bring players irrespective of their educational background under a common e-gaming framework and present the STEM concepts in the form of puzzles. The game has been designed in such a way that age does not stand as a barrier. It can, therefore, be a nice addition to the category of GWAP that teach kids several STEM concepts right from an early age. Being a STEMbased game, it was observed that the participation of players from the non-STEM background was much less. The participation of females was also lesser than males. Based on the feedback obtained from the existing players it was found that improving the gaming interface and presenting the difficult puzzles in the game with a pleasing visualization can increase the overall participation of the game. Addition of intuitive tools in the gaming framework that eases the gameplay experience can also act in favor of increasing the overall participation in the game.

UNTANGLED III gaming platform also brought into light some interesting observations. The different kinds of moves and strategies that the males and the females used and also the order in which they played the puzzles were some of the key factors that were taken into consideration in the study. We wanted to see whether there were any differences in the type of moves chosen by the males and the females, whether there were any stark differences in the gameplay strategies between the males and the females. Interestingly the data showed no such differences among the players of both genders. Moreover, the variety of puzzles chosen by the males and the females were also the same. The puzzles in the game were unlocked, and there was no specific order that the players had to follow. Hence, we wanted to see whether the males chose different puzzles of different difficulty levels than females. The data for both the genders did not point to any dissimilar trends. However, it was apparent from the data of the females that unlike males they tended to start with the easier puzzles in the very beginning and then steadily increased the difficulty of the puzzles being attempted.

Similar gameplay strategies and performance measures between the males and females clearly indicates at par competence of both the males and the females. We aim to incorporate the feedback obtained from the existing players into UNTANGLED III and to any subsequent versions of UNTANGLED gaming lineup that would increase the overall participation of players from any age and educational background. The suggestions that are obtained from the outreach events will also be incorporated for the same cause and especially focused on increasing female participation in the game and as a consequence into STEM disciplines.

\section{ACKNOWLEDGMENT}

We would like to thank the National Science Foundation for supporting this work with grant NSF CCF-1617475.

\section{REFERENCES}

[1] L. Straker, R. Abbott, R. Collins, and A. Campbell, "Evidence-based guidelines for wise use of electronic games by children," Ergonomics, vol. 57, no. 4, pp. 471-489, 2014, doi: 10.1080/00140139.2014.895856.

[2] M. D. Dickey, "Game design and learning: a conjectural analysis of how massively multiple online role-playing games (MMORPGs) foster intrinsic motivation," Educational Technology Research and Development, vol. 55, no. 3, pp. 253-273, Jun. 2007, doi: 10.1007/s11423-006-9004-7.

[3] M. J. Koepp et al., "Evidence for striatal dopamine release during a video game," Nature, vol. 393, p. 266, 1998, doi: $10.1038 / 30498$.

[4] M. J. Mayo, "Games for science and engineering education," Commun. ACM, vol. 50, no. 7, pp. 30-35, Jul. 2007, doi: 10.1145/1272516.1272536.

[5] B. Elena and S. Karen, Learning, education and games. Pittsburgh, PA, USA: ETC Press, 2014, pp. 23-36.

[6] M. J. Mayo, "Video games: A route to large-scale STEM education?," Science, vol. 323, pp. 79-82, 2009, doi: 10.1126/science. 1166900 .

[7] Y.-T. Wu and O. R. Anderson, "Technology-enhanced stem (science, technology, engineering, and mathematics) education," Journal of Computers in Education, vol. 2, pp. 245-249, 2015, doi: 10.1007/s40692-015-0041-2.

[8] A. Shaw, "Do you identify as a gamer? Gender, race, sexuality, and gamer identity," New Media \& Society, vol. 14, pp. 28-44, 2012, doi: 10.1177/1461444811410394.

[9] J. Winn and C. Heeter, "Gaming, gender, and time: Who makes time to play?," Sex Roles, vol. 61, pp. 1-13, 2009, doi: 10.1007/s11199-009-9595-7.

[10] J. Cassell and H. Jenkins, From barbie ( $r$ ) to mortal kombat. MIT Press Ltd, 2000.

[11] W.-H. D. Huang, D. W. Hood, and S. J. Yoo, "Gender divide and acceptance of collaborative Web 2.0 applications for learning in higher education," The Internet and Higher Education, vol. 16, pp. 57-65, 2013, doi: 10.1016/j.iheduc.2012.02.001.

[12] T. Hartmann and C. Klimmt, "Gender and computer games: Exploring females' dislikes," Journal of Computer-Mediated Communication, vol. 11, pp. 910-931, 2006, doi: 10.1111/j.1083-6101.2006.00301.x. 
[13] W. J. Tippett et al., "Convergent validity and sex differences in healthy elderly adults for performance on 3D virtual reality navigation learning and $2 \mathrm{D}$ hidden maze tasks," CyberPsychology \& Behavior, vol. 12, pp. 169-174, 2009, doi: 10.1089/cpb.2008.0218.

[14] M. Tlauka, A. Brolese, D. Pomeroy, and W. Hobbs, "Gender differences in spatial knowledge acquired through simulated exploration of a virtual shopping centre," Journal of Environmental Psychology, vol. 25, pp. 111-118, 2005, doi: 10.1016/j.jenvp.2004.12.002.

[15] M. Ingalhalikar et al., "Sex differences in the structural connectome of the human brain," Proceedings of the National Academy of Sciences, vol. 111, pp. 823-828, 2014, doi: 10.1073/pnas.1316909110.

[16] C. Shen, R. Ratan, Y. D. Cai, and A. Leavitt, "Do men advance faster than women? Debunking the gender performance gap in two massively multiplayer online games," Journal of Computer-Mediated Communication, vol. 21, pp. 312-329, 2016, doi: 10.1111/jcc4.12159.

[17] A. K. Sistla, K. Patel, and G. Mehta, "Crowdsourcing the mapping problem for design space exploration of custom reconfigurable architecture designs," Human Computation, vol. 2, 2015, doi: 10.15346/hc.v2i1.5.
[18] G. Mehta et al., "UNTANGLED: A game environment for discovery of creative mapping strategies," $A C M$ Transactions on Reconfigurable Technology and Systems (TRETS), vol. 6, p. 13, 2013, doi: 10.1145/2517325.

[19] G. Mehta, K. Patel, and N. S. Pollard, "On fast iterative mapping algorithms for stripe based coarse-grained reconfigurable architectures," International Journal of Electronics, vol. 102, pp. 3-17, 2014, doi: 10.1080/00207217.2014.938310.

[20] G. Mehta, K. K. Patel, N. Parde, and N. S. Pollard, "Datadriven mapping using local patterns," IEEE Transactions on Computer-Aided Design of Integrated Circuits and Systems, vol. 32, pp. 1668-1681, 2013, doi: 10.1109/tcad.2013.2272541.

[21] S. Cooper et al., "The challenge of designing scientific discovery games," in Proceedings of the fifth international conference on the foundations of digital games, New York, NY, USA, 2010, pp. 40-47, doi: 10.1145/1822348.1822354.

[22] R. Koodli, B. Keep, K. R. Coppess, F. Portela, E. Players, and R. Das, "RNA design movesets and strategies from an Internet-scale videogame," bioRxiv, p. 326736, 2019, doi: $10.1101 / 326736$. 